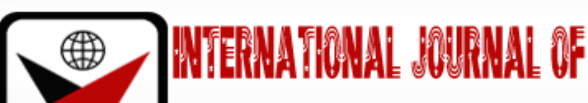

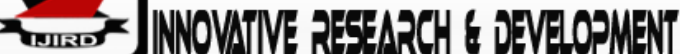

ISSN 2278-0211 (Online)

\section{Nutritional and Safety Surveillance Study of Some Puppies' Commercial Dry Foods}

\author{
Noha Abdelrahman \\ Researcher, Department of Chemistry, \\ Animal Health Research Institute, Malnutrition Unit, Egypt
}

T. M. Melegy

Lecturer, Department of Nutrition and Clinical Nutrition, Cairo University, Egypt

El-Banna R

Professor and Head of Nutrition and Clinical Nutrition Department, Medicine Cairo University, Egypt

Samia El-zeini

Professor, Department of Food Hygiene, Animal Health Research Institute, Egypt

\begin{abstract}
:
A surveillance study was conducted to evaluate the nutritional value and safety of some puppies' commercial dry foods available in Egypt. A total of (100) extruded puppies' dry food samples (18 imported and 2 locally produced) were collected from different batches and subjected to proximate analysis for determinations of Moisture, Crude protein, Ether extract, Crude fiber and total ash\%. Moreover, all samples were examined for their water activity values as well as Mycotoxins levels (Aflatoxins and Ochratoxins). Results of proximate analysis in comparison with the values stated on the bag label revealed that, moisture ranged from 4.95 to $11.36 \%$, CP ranged from 23.37 to $40.96 \%$, EE ranged from 5.35 to 19.21, CF ranged from 1.30 to $4.19 \%$ and total ash ranged from 3.48 to $12.49 \%$. Water activity values $\left(a_{w}\right)$ ranged from 0.43 to 0.71 in comparison to the standard acceptable level of 0.6 for dry food, a condition that may be explained on the basis that the examined puppies' dry foods might be subjected to excessive dryness during the manufacture as a tool for protection against microbial growth. Results of Aflatoxins levels revealed that all samples were proved to be positive for the presence of Aflatoxins, 30\% of them were over the permissible limits, which ranged from 1.2 to 17.6 ppb. Furthermore, all examined samples were proved to be positive for Ochratoxins with minimum and maximum levels of 3.9 and $42.3 \mathrm{ppb}$ respectively.
\end{abstract}

Keywords: Puppies' dry food, proximate analysis, Mycotoxins, Water activity

\section{Introduction}

Prior to the middle of the nineteenth century, pet owners fed their pets a homemade food because commercial pet foods were not available. Recently, pet owners have become interested in both quality and safety of foods that they fed their pets, they pay most attention to select a product able to provide optimal nutritional requirement, promote long-term health sustainability, highly palatable and of better economic return. Proximate chemical composition is the primary indicator that could be used for nutritional value evaluation of food since it provides a basic data help in diet formulation, yet it does not concern the palatability and bioavailability of different nutrients. Moreover, water activity (aw) and mycotoxins levels are indicators that should be determined during dry pet food safety evaluation.

Water activity can be defined as the water's energy status in a product (unbound or free water) which its value ranges from 0 to 1.0. Water activity is already used since the 1960's in commercial pet foods. Moreover, moisture content provides information concerning product quality, but it cannot be regarded as the effective tool for product quality and safety because it describes the total water amount (both bound and free) without specification separately, and only unbound water is responsible for product microbial contamination and spoilage. Moisture content may be higher than the allowable levels, but if the water activity is adequately low, the microorganisms cannot use the water to maintain their growth. Both moisture and water activity are important measures, but water activity is the only measure which can be considered as the most effective tool providing the most valuable data about product quality and safety. Drying pet food below a critical water activity level can be an effective way for microbial growth control (1). Baser and Yalcin (2017) carried out a surveillance study on 36 sample of both dog and cat extruded dry food available in Turkish market to evaluate their quality characteristics. They subjected samples to water activity and moisture analysis and found that water activity mean recorded 0.41 and 0.44 , moisture content was $5.80 \%$ and $6.44 \%$ for cat and dog foods respectively. They stated that samples are safe, durable and not susceptible to any distortion. 
Another important factor that determines the safety of dry pet food is its content of mycotoxins ${ }^{(2,3)}$. Dry dog food should not have any fungi contamination and the maximum allowable Aflatoxin B1 limit in mixed foods for dogs were set at $10 \mu \mathrm{g} / \mathrm{kg}\left({ }^{4}\right)$. Chronic Aflatoxin exposure with a range between 0.05 to $0.3 \mathrm{mg}$ Aflatoxins per kg pet food over 6-8 weeks is characterized by lethargy, anorexia, intravascular coagulation and jaundice (5). The daily dose of $0.2 \mathrm{mg}$ Ochratoxins $/ \mathrm{kg}$ BW for 2 weeks or a single dose of $7.8 \mathrm{mg}$ Ochratoxins $/ \mathrm{kg} \mathrm{BW}$ was lethal to young beagle dogs (6).

Dogs are highly sensitive to mycotoxins toxicity, and several mycotoxins' outbreaks have been reported in commercial pet foods. A recall on December 20, 2005 was posted by the U.S Food and Drug Administration, where nineteen of different pet food types produced at a single facility in Gaston, South Carolina were excluded from the sale, aflatoxins were proved to contaminate about sixteen batches of pet food at levels greater than or equal to $20 \mathrm{ppb} .100 \mathrm{dogs}$ died in weeks within this outbreak, thus the veterinarians were alarmed (7). The Ochratoxin A (OTA) concentrations were measured in some commercial dog and cat food, 19 samples were contaminated with OTA and 21 samples contained no detectable concentrations of OTA, $13.1 \mu \mathrm{g} / \mathrm{kg}$ was the highest measured level which had been detected in dry dog foods (8). A total of 60 sample of dry and wet dog food available in California; USA were examined for existence of 11 type of mycotoxins (Aflatoxins B1, B2,G1 and G2; Deoxynivalenol; Fumonisin B1, B2; HT-2 toxin; Ochratoxin A; T-2 toxin and Zearalenone). Results revealed measurable mycotoxin concentrations in dry dog foods containing grains but not in grainfree dry dog foods, or in wet foods either containing grains or grain-free. This study suggests that the risk of mycotoxin exposure is higher in dry dog foods containing grains.

The caloric distribution in dog food during growth was recommended to be $41 \%$ of energy supplied from fat, $32 \%$ from carbohydrates and $27 \%$ from protein (9). The minimum protein concentration for growth was increased slightly from $22 \%$ to $22.5 \%$ DM (10), and $25 \%$ (< 14 weeks of age) while $22 \%$ ( $>14$ weeks of age) for maximum nitrogen retention (11). The dietary fat requirements as a DM percent for dogs from weaning to adulthood ranged from 10 to $25 \%$ (12). Carbohydrates can be included in dry foods for dogs with a range of $30 \%$ to $60 \%$ (13). The crude fiber can be supplemented up to 5\% in dog diets (14). Ash percent of high-quality dry pet foods generally range from 5-8 percent (15). Nowadays a wide variety of imported and few locally produced commercial dry dog foods for different health conditions, life stages, physiological states and activity levels are currently available in the Egyptian market and used widely in practical dog feeding. However, the exact nutrient contents and their safety are not well established yet.

On the basis of the above-mentioned data, the exact nutrient contents of puppy stage dry foods and their safety are not well established yet. So that, the objective of the present study was to evaluate the nutritional value and safety of most of the imported and locally produced commercial dry dog foods available in the Egyptian market in order to offer the surveillance results to dog owners as a reference.

\section{Materials and Methods}

\subsection{Sample Collection}

A total of (100) extruded dry dog food samples for puppy stage were randomly collected from 18 different imported foods and from 2 types of locally produced foods (different batches) from different localities available in the Egyptian market. The collected samples having the following trade names $\left(\right.$ Brit $\AA$, Josera Junior $1 \AA$, Mera dog Junior1 $\AA^{\circledR}$,

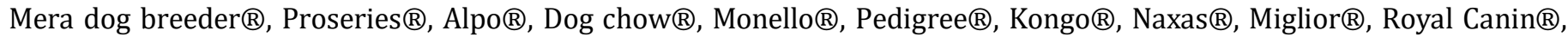

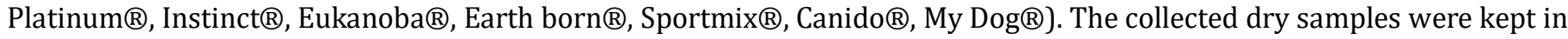
tightly closed containers and stored for further examination

\subsection{Proximate Analysis}

The collected samples were subjected to proximate analysis for determination of Moisture, CP, EE, CF and total ash\%, according to AOAC (2000) (16). All analytical procedures were carried out in Animal Nutrition Integrated Solutions Laboratory (ANIS).

\subsection{Determination of Aflatoxins and Ochratoxins levels}

The collected samples were subjected to detect and measure both of aflatoxins and ochratoxin levels using VICAM device with S/N 0383

\subsection{Determination of Water Activity $\left(A_{w}\right)$}

All the collected samples were examined for their water activity values by using NOVASINA AG Lab Master $\mathrm{a}_{\mathrm{w}}$ device with S/N 1203016, 2014 device (Switzerland).

\section{Discussion}

The results of the average proximate chemical composition of the collected puppies' food samples are illustrated in table (1). Results concerning the average crude protein contents of food samples revealed a wide diversity of their crude protein content since the CP\% ranged from 23.37 to 40.96; about 60 out of 100 tested samples $(60 \%)$ were found to be lower in their crude protein content in comparison to the values stated on their bag label, only $15 \%$ of the tested samples were almost close to their bag label values, while the rest (25\%) were higher in their tested protein values than the bag label ones.

These values appeared to be almost close to protein requirement recommendations for puppies; 26 to $28 \%$ for large and giant dog breeds (17) and 25\% ( $<14$ weeks of age) while $22 \%$ ( $>14$ weeks of age) for maximum nitrogen retention (11). The reduced protein values in most of the commercially puppies' dry foods may result in miss calculation of 
the energy intake for puppies which adversely affect their performance. Meanwhile, samples that recorded higher protein values may not only result in miss calculation of the energy intake but also may lead to nitrogen smell in puppies' excreta, as the higher undigested protein in the hind gut may result in greater protein putrefaction (18-21).

Results concerning the ether extract (EE) content of the tested puppies' food samples (table 1) showed a great variation in their EE percent, as it ranged from 5.35 to 19.21; about 75\% of the tested food samples were found to be lower than their bag label values, while $15 \%$ of the tested samples were higher than their bag label values and the rest (10\%) were almost a little bit exceed their bag label values. EE \% requirement on the DM basis for dogs from weaning to adulthood ranged from 10 to 25 (12). Our findings appear to be almost close to fat requirement with a minimum value of $8 \%$, with few exceptions (22). It is a well-established fact that fat contents in the puppies' diet appeared to be crucial during their growth, especially when nutritionists recommended the caloric distribution during growth to be $41 \%$ of energy supplied from fat, $27 \%$ from protein and $32 \%$ from carbohydrates $(9)$. The consequence of reduced crude fat values in $75 \%$ of the tested samples may also result in miss calculation of the food energy density equation, and therefore misses calculation of energy and food intake.

Results illustrating the crude fiber contents of different samples (table 1) showed that the CF\% ranged from 1.30 to 4.19 , about $85 \%$ of the tested samples were found to be below their maximum label values, while the other $15 \%$ were almost a little bit exceed their label values. These results appeared to be almost close to fiber recommendations for dogs; up to $5 \%$ in dog diets (14). The results of crude fiber contents of the collected food samples which indicated that about $85 \%$ of the tested samples were much lower than their bag label values are debatable, as crude fiber promotes comfortable digestion and normal colonocytes health. The lower fiber of these samples may indicate the use of animal protein sources over the plant ones. From the economic point of view, many dog food formulators tend to use animal protein wastes in a high inclusion rate at the expense of the higher cost plant protein sources such as soybean meal. It is a well recognized that the inclusion of animal protein wastes in dog food may predispose to microbial contamination and/or recontamination of these diets alternatively.

In addition, rendered animal protein by-products are mostly overloaded with microorganisms according to the National Renderers Association (NRA) report (23). Several types of microorganisms were isolated from rendered poultry by-products (24). Rendered animal co-products were proved to be contaminated with a high number of microorganisms (25). Aspergillus fumigatus and Penicillium spp were isolated from rendered samples (26). These findings also confirm our opinion regarding the intended decrease in moisture content through excess dryness by a number of dog food producing companies in an attempt to decrease the water activity or the free water for microbial growth prevention.

The results indicating the total ash contents of different samples (table 1) showed that the total ash \% ranged from 3.48 to 12.49 . Results revealed that about $20 \%$ of the tested samples were higher in the total ash $\%$ than that widely recommended in the available literatures. The high-quality dry pet foods generally contain between $5-8 \%$ ash (15). The higher total ash content of the examined food samples may contribute to the dilution of the amounts of nutrients available to the animal 'un published results'. In a more specific view for ash results, we assume that high ash content may be related to high inclusion levels of rich ash ingredients such as meat and bone meal, limestone, dicalcium phosphate, monocalcium phosphate and salt by a level differ from the written label ingredient formula and/or the high inclusion of yeast as an alternative protein source at the expense of other good quality proteins like soya, meat meal and fish meal.

Results concerning the water activity values $\left(\mathrm{a}_{\mathrm{w}}\right)$ of different samples which illustrated in table (3) showed that the water activity values ranged from 0.43 to 0.71 . It was noticed that only 5 out of 100 examined food samples were higher than the standard acceptable level $(0.6)$ for dry food.

Concerning the moisture content of different samples (table 1) showed that the moisture \% ranged from 4.95 to 11.36 . It was obvious that 50 samples out of 100 samples tested for moisture content were lower than $6 \%$ moisture content, a situation that may indicate that there is an intended excessive dryness of most of the tested puppies' dry foods during processing in order to reduce their moisture content.

Furthermore, results indicated that if we compare the values of moisture content to the corresponding values of water activity for most of the examined samples, it could be noticed that, samples that had moisture content values of less than $6 \%$, their water activity values $\left(\mathrm{a}_{\mathrm{w}}\right)$ ranged from 0.43 to 0.49 and samples that had moisture content values of higher than $6 \%$, their water activity values $\left(\mathrm{a}_{\mathrm{w}}\right)$ ranged from 0.48 to 0.71 . These values were considered to be normal and expected as samples with higher moisture content might have higher water activity values and vice versa. But when we look at some samples' results individually, we could find that some samples of moisture contents $7.1,5.5$ and $4.95 \%$ had almost the same water activity value of 0.49 . When the sample number 10 had $11.36 \%$ moisture and an $a_{w}$ value of 0.71 ; this may be explained on the basis of one or more of the following possibilities, firstly it might be due to insufficient dryness during manufacture, secondly, it might be due to insufficient amount or low quality of emulsifiers or not using emulsifiers at all, lastly might be occurred as a result of using low quality fat or oil that might result in a higher ratio of unbound free water.

In a more specific view for water activity and moisture results and their relation with fat results, we extrapolated that puppies' dry food manufacturing companies used one or more methods in an attempt to lower microbial growth chance by lowering water activity; either by excessive dryness or emulsifiers use. For example; sample number 1 and 19 analytical results are $15.85 \%$ and $11.39 \%$ for fat content, 0.49 and 0.51 for water activity and $4.95 \%$ and $7.5 \%$ for moisture content respectively, from the logic point of view when sample number 1 had higher fat percent than sample number 19, it would have higher water activity consequently, but we found the reverse results which indicated the excessive dryness of sample number 1 as a trial to keep the safety margin by decrease the water activity. Sample number 13 and 5 are another example for water activity control, but by another method; their analytical results revealed that fat contents are $10.54 \%$ and $5.35 \%$, moisture contents are $7.23 \%$ and $5.53 \%$ and water activity values are 0.48 and 0.49 
respectively, however the water activity value of sample number 13 was lower than sample number 5, but its moisture content was higher than sample number 5, so we assumed emulsifiers use in sample number 13 as an attempt to control water activity value without affecting protein quality, digestibility and vitamins stability via excessive dryness which is not a small issue regarding international dog food manufacturing companies.

It is a well-established fact that product quality couldn't be determined through its moisture content, because it includes bound and free water, and pet food microbial contamination is related to free water (water activity) only. So, measuring the free water (water activity) is considered as a more accurate indicator for the food safety. More or less similar explanations were reported $(27,1)$. It could be concluded that the excessive dryness of puppies' dry foods during manufacture might be the main factor responsible for the lowered water activity values. However, further research activities are required to visualize the effect of the excess heat dryness on the protein quality and digestibility, vitamins stability and other nutrients availability. Pet food producing companies shouldn't depend only on excess heat dryness to reduce water activity values, but also a great concern should be given to tools such as using a good emulsifier and a suitable level of good quality fat in pet foods.

Results illustrating both Aflatoxins and Ochratoxins levels detected in different collected puppies' dry food samples (table 2) showed that all samples (100\%) proved to be positive for the presence of both Aflatoxins and Ochratoxins but with varied concentrations. For Aflatoxins, their levels ranged from 1.2 to $17.6 \mathrm{ppb}$. A total of 30 out of 100 examined puppies' dry food samples contain higher Aflatoxins levels than the permissible limits (10 ppb) for animal feeds in Egypt. These findings come in accordance with some literatures reported that the dry dog food should not have any fungi contamination and the maximum allowable Aflatoxin B1 limit in mixed feeds for dogs and horses were set at10 $\mu \mathrm{g} / \mathrm{kg}(4)$.

Concerning the Ochratoxins, their levels ranged from 3.9 to 42.3 ppb. There are no specific legal permissible limits for Ochratoxins according to the Egyptian standard regulation. However, these levels may indicate a health hazard threat in the dog real-life, especially under unfavorable environmental, nutritional, physiological and disease conditions (8). Kidneys are the primary Ochratoxin accumulation organ and the daily dose of $0.2 \mathrm{mg}$ Ochratoxin/ $\mathrm{kg}$ BW for 2 weeks as a daily dosage or a single dose of $7.8 \mathrm{mg}$ Ochratoxins/kg BW was lethal to young beagle dogs (6). Ochratoxins levels were measured in some commercial dog and cat food, 19 samples were contaminated with Ochratoxins with the highest level of $13.1 \mu \mathrm{g} / \mathrm{kg}$ food, the main sources of Ochratoxins contamination can be either related to incorporation of cereals or slaughtered animal viscera which are widely used in canned food production (8).

The results of this survey highlight the importance of not only the inspection of the nutritional quality, but also the safety of the puppies' dry foods. It is worth to say that much research activities are required to ameliorate the effect of the excess heat dryness on the protein quality and nutrients availability, nonetheless, the hazard threat of undefined limits of mycotoxins in dog foods.

\section{Results}

\begin{tabular}{|c|c|c|c|c|c|c|c|c|c|c|c|c|c|c|c|}
\hline 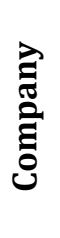 & 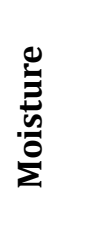 & & & \multicolumn{3}{|l|}{ 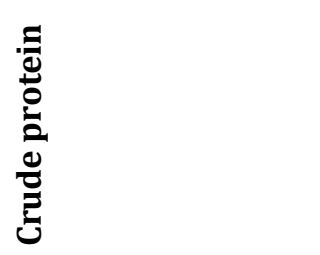 } & \multicolumn{3}{|l|}{ 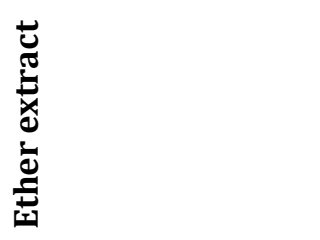 } & \multicolumn{3}{|l|}{ 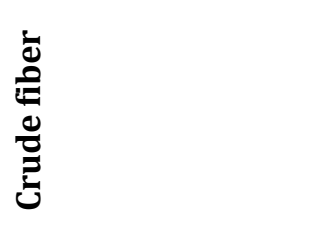 } & \multicolumn{3}{|l|}{$\begin{array}{l}\frac{5}{\tilde{\pi}} \\
\frac{\pi}{\pi} \\
\stackrel{\tilde{0}}{0}\end{array}$} \\
\hline & \multicolumn{3}{|c|}{ \%)) } & \multicolumn{3}{|c|}{$(\%)$} & \multicolumn{3}{|c|}{ \%)) } & \multicolumn{3}{|c|}{$(\%)$} & \multicolumn{3}{|c|}{ \%)) } \\
\hline & Mean & SE & Label & Mean & SE & Label & Mean & SE & Label & Mean & SE & Label & Mean & SE & Label \\
\hline 1 & 4.95 & 0.4 & 10 & 28.65 & 0.6 & 30 & 15.85 & 0.66 & 21 & 1.38 & 0.21 & 2 & 7.99 & 0.8 & 6.5 \\
\hline 2 & 5.1 & 0.5 & -.-.-* & 24.22 & 0.7 & 26 & 10.25 & 0.8 & 14 & 1.66 & 0.2 & 2.5 & 10.03 & 0.65 & 7 \\
\hline 3 & 5.21 & 0.4 & 10 & 24.93 & 0.5 & 26 & 19.21 & 1 & 16 & 2.45 & 0.3 & 3.5 & 8.05 & 0.66 & ---* \\
\hline 4 & 5.88 & 0.51 & ----.* & 27.68 & 0.6 & 29 & 11.35 & 0.77 & 16 & 1.45 & 0.32 & 2 & 6.07 & 0.74 & 6.5 \\
\hline 5 & 5.53 & 0.52 & 12 & 26.03 & 0.5 & 26 & 5.35 & 0.85 & 10 & 2.53 & 0.23 & 5 & 9.9 & 1.1 & ---* \\
\hline 6 & 6.2 & 0.3 & 12 & 27.6 & 0.7 & 27 & 10.29 & 0.97 & 10 & 1.67 & 0.35 & 3.5 & 6.01 & 0.96 & 8 \\
\hline 7 & 5.49 & 0.33 & 9 & 27.43 & 1 & 29 & 9.93 & 0.63 & 17.5 & 2.77 & 0.25 & 2.7 & 3.48 & 0.85 & 7 \\
\hline 8 & 7.1 & 0.4 & ----_* & 30.26 & 1.1 & 30 & 9.06 & 0.75 & 16 & 2.43 & 0.3 & 2.5 & 8.47 & 0.5 & 8.2 \\
\hline 9 & 5.45 & 0.42 & ----* & 25.72 & 1.2 & 27 & 8.78 & 1.1 & 14 & 1.47 & 0.4 & 2 & 6.62 & 0.4 & 6.3 \\
\hline 10 & 11.36 & 0.5 & 9 & 26.87 & 0.8 & 28 & 8.04 & 0.34 & 16 & 2.36 & 0.3 & 3.5 & 3.76 & 0.7 & 7.5 \\
\hline
\end{tabular}




\begin{tabular}{|c|c|c|c|c|c|c|c|c|c|c|c|c|c|c|c|}
\hline 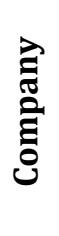 & \multicolumn{3}{|l|}{$\begin{array}{l}\stackrel{0}{\Xi} \\
\stackrel{5}{0} \\
\stackrel{0}{\Sigma}\end{array}$} & 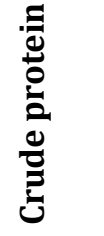 & & & \multicolumn{3}{|l|}{ 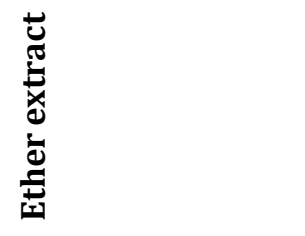 } & \multicolumn{3}{|l|}{ 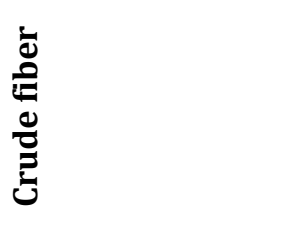 } & \multicolumn{3}{|l|}{ 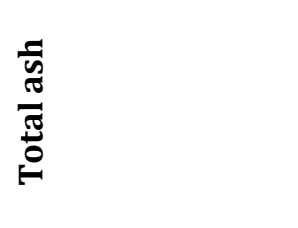 } \\
\hline $\begin{array}{l}\bar{\Xi} \\
\bar{\Xi} \\
\bar{\Xi}\end{array}$ & \multicolumn{3}{|c|}{ \%)) } & \multicolumn{3}{|c|}{ (\%) } & \multicolumn{3}{|c|}{ \%)) } & \multicolumn{3}{|c|}{ (\%) } & \multicolumn{3}{|c|}{ \%)) } \\
\hline 11 & 7.69 & 0.45 & 10 & 23.37 & 0.7 & 26 & 13.48 & 1.2 & 9 & 3.27 & 0.22 & 3 & 4.43 & 0.6 & 6 \\
\hline 12 & 6.44 & 0.35 & 10 & 33.86 & 1.3 & 29 & 13.37 & 0.9 & 18 & 1.41 & 0.3 & 3.5 & 8.63 & 0.56 & --.--* \\
\hline 13 & 7.23 & 0.5 & 12 & 26.27 & 1 & 26 & 10.54 & 0.82 & 12 & 1.3 & 0.23 & 5 & 5.98 & 0.7 & --.-** \\
\hline 14 & 4.99 & 0.3 & 12 & 25.6 & 0.5 & 26 & 12.03 & 0.5 & 15 & 2.4 & 0.31 & 4 & 7.48 & 0.5 & 8 \\
\hline 15 & 5.72 & 0.2 & 10 & 27.64 & 0.66 & 29 & 12.64 & 0.54 & 18 & 1.59 & 0.23 & 4 & 7.76 & 0.66 & 6.67 \\
\hline 16 & 5.38 & 0.34 & 10 & 40.96 & 0.75 & 38 & 17.63 & 0.66 & 20 & 1.81 & 0.32 & 2.5 & 10.21 & 0.45 & 12 \\
\hline 17 & 6.31 & 0.3 & 10 & 25.5 & 1.4 & 28 & 9.27 & 0.58 & 12 & 1.5 & 0.4 & 3 & 12.49 & 0.8 & 7 \\
\hline 18 & 6.98 & 0.4 & 10 & 29.44 & 0.68 & 28 & 13.07 & 0.44 & 20 & 4.19 & 0.31 & 4 & 5.29 & 0.84 & --.-* \\
\hline 19 & 7.5 & 0.4 & 10 & 29.2 & 0.8 & 27 & 11.39 & 1.2 & 11 & 2.04 & 0.2 & 2.8 & 6.73 & 0.88 & 8 \\
\hline 20 & 6.28 & 0.5 & -----** & 28.4 & 0.68 & 29 & 18.18 & 0.79 & 16 & 1.54 & 0.24 & 2 & 5.42 & 0.78 & 6.5 \\
\hline
\end{tabular}

Table 1: Proximate Chemical Composition of Different Collected Samples

(5 Samples/Company) (Mean Values with Their Standard of Error)

*These Values Are Not Illustrated on the Bag Label

\begin{tabular}{|c|c|c|c|c|}
\hline \multirow[t]{4}{*}{ Company Number } & \multicolumn{4}{|c|}{ Mycotoxins Levels } \\
\hline & \multicolumn{4}{|c|}{$(\mu \mathrm{g} / \mathrm{kg})$} \\
\hline & \multicolumn{2}{|c|}{ Aflatoxins } & \multicolumn{2}{|c|}{ Ochratoxins } \\
\hline & Mean & SE & Mean & SE \\
\hline 1 & 2 & 0.2 & 9.2 & 0.7 \\
\hline 2 & 13.9 & 0.21 & 41.5 & 1.5 \\
\hline 3 & 17.6 & 0.3 & 19.1 & 1.8 \\
\hline 4 & 16.5 & 0.22 & 42.3 & 1.9 \\
\hline 5 & 11.8 & 0.34 & 8.5 & 0.6 \\
\hline 6 & 2.9 & 0.25 & 3.9 & 0.26 \\
\hline 7 & 7.1 & 0.5 & 17.4 & 0.7 \\
\hline 8 & 4.3 & 0.4 & 26.7 & 1.2 \\
\hline 9 & 7.9 & 0.43 & 24.2 & 1.3 \\
\hline 10 & 1.2 & 0.18 & 4.5 & 0.3 \\
\hline 11 & 3.9 & 0.3 & 9.9 & 0.5 \\
\hline 12 & 4.2 & 0.26 & 3.9 & 0.2 \\
\hline 13 & 11.4 & 0.45 & 11.3 & 0.2 \\
\hline 14 & 10.4 & 0.6 & 20.8 & 0.7 \\
\hline 15 & 1.7 & 0.1 & 6.3 & 0.5 \\
\hline 16 & 4.7 & 0.2 & 16 & 0.7 \\
\hline 17 & 3.3 & 0.1 & 12.3 & 0.77 \\
\hline 18 & 1.3 & 0.1 & 4.3 & 0.34 \\
\hline 19 & 8.5 & 0.4 & 6.5 & 0.45 \\
\hline 20 & 9.8 & 0.6 & 19.4 & 0.8 \\
\hline
\end{tabular}

Table 2: Mycotoxins Levels of Different Collected Samples (5 Samples/Company)

(Mean Values with Their Standard of Error) 


\begin{tabular}{|c|c|c|}
\hline \multirow[t]{3}{*}{ Company Number } & \multirow{2}{*}{\multicolumn{2}{|c|}{$\frac{\text { Water Activity }}{\text { (Value) }}$}} \\
\hline & & \\
\hline & Mean & SE \\
\hline 1 & 0.49 & 0.01 \\
\hline 2 & 0.47 & 0.02 \\
\hline 3 & 0.48 & 0.01 \\
\hline 4 & 0.43 & 0.03 \\
\hline 5 & 0.49 & 0.02 \\
\hline 6 & 0.5 & 0.01 \\
\hline 7 & 0.48 & 0.01 \\
\hline 8 & 0.49 & 0.02 \\
\hline 9 & 0.47 & 0.02 \\
\hline 10 & 0.71 & 0.03 \\
\hline 11 & 0.52 & 0.01 \\
\hline 12 & 0.48 & 0.01 \\
\hline 13 & 0.48 & 0.03 \\
\hline 14 & 0.48 & 0.02 \\
\hline 15 & 0.47 & 0.02 \\
\hline 16 & 0.44 & 0.01 \\
\hline 17 & 0.49 & 0.01 \\
\hline 18 & 0.5 & 0.02 \\
\hline 19 & 0.51 & 0.01 \\
\hline 20 & 0.5 & 0.02 \\
\hline
\end{tabular}

Table 3: Water Activity Values of Different Collected Samples (5 Samples/Company)

(Mean Values with Their Standard of Error)

\section{References}

i. Carter B. \& Fontana A. (2008) Water activity: the key to pet food quality and safety. http://www.aqualab.com/assets/Uploads/AN-Water-Activity-The-Key-to-Pet-Food.pdf (accessed June 2014).

ii. Stenske KA, Smith JR, Newman SJ, et al. (2006) Aflatoxicosis in dogs and dealing with suspected contaminated commercial foods. J.Am. Vet. Med. Assoc. 228, 1686-1691.

iii. Garland T\& Reagor J (2001) Chronic canine aflatoxicosis and management of an epidemic. In Hand book of Mycotoxins and Phycotoxins in Perspective at the Turn of the Millennium, pp. 231-236

iv. Coulombe JAR (1993) Biological action of mycotoxins. J.Dairy Sci.76, 880-891

v. Boermans HJ\& Leung MCK (2007) Mycotoxins and the pet food industry: Toxicological evidence and risk assessment. International Journal of Food Microbiology 119,95-102

vi. Szczech GM, Carlton WW, Tuite J (1973) Ochratoxicosis in Beagle dogs. I. Clinical and clinicopathological features. Vet. Pathol. 10, 135-154.

vii. Aquino S \& Corrêa B (2011) Aflatoxins in Pet Foods: A Risk to Special Consumers. In Handbook of Aflatoxins Detection, Measurement and Control, pp. 53-74

viii. Razzazi E, Böhm J, Grajewski J, et al. (2001) Residues Of Ochratoxin A In Pet Foods, Canine And Feline Kidneys. J. Anim. Physiol. a. Anim. Nutr. 85, 212-216

ix. Case LP, Hayek MG, Daristotle L, et al. (2011) Nutrient content of pet food. In Hand book of Canine and Feline Nutrition, 3rd ed., pp. 141-162

x. National Research Council (2006) Nutrient Requirements of Dogs and Cats. Washington, DC: National Academy Press.

xi. F.E.D.I.A.F. (2008) Federation Europeenne de I'Industrie de Alimentis pour Animaux Familiers Nutritional Guidelines for Complete and Complementary Pet Food for Cats and Dogs.

xii. Debraekeleer J, Gross KL, Zicker SC (2010) Feeding growing puppies: postweaning to adulthood. In Hand book of Small animal clinical nutrition, 5th. Ed., pp. 311-319

xiii. Carciofi AC, Takakura FS, de-Oliveira LD, et al. (2008) Effects of six carbohydrate sources on dog diet digestibility and post-prandial glucose and insulin response. Journal of Animal Physiology and Animal Nutrition 92,326-336.

xiv. Debraekeleer J, Gross KL, Zicker SC (2010) Feeding young adult dogs: Before middle age. In Hand book of Small animal clinical nutrition, 5th. Ed., pp. 257-272

xv. Case LP, Hayek MG, Daristotle L, et al. (2011) Energy and water. In Hand book of Canine and Feline Nutrition, 3rd ed., pp. 3-12

xvi. AOAC (2000) Official methods of analysis. Association of Official Analytical Chemists. Arlington. Virginia, USA.

xvii. Lepine AJ (2002) Optimal nutrition for the growing retriever and upland dog. In Hand book of Nutrition and care of the sporting dog, Dayton, Ohio, the Iams Company, pp 17-22

xviii. Nery J, Goudez R, Biourge V, et al. (2012) Influence of dietary protein content and source on colonic fermentative activity in dogs differing in body size and digestive tolerance. J ANIM SCI. 90, 2570-2580 
xix. Yamka RM, Jamikorn U, True AD, et al. (2003) Evaluation of low-ash poultry meal as a protein source in canine foods. J. ANIM. SCI. 8,2279-2284

xx. Hughes R, Magee EA, Bingham S (2000) Protein degradation in the large intestine: relevance to colorectal cancer. Curr. Issues Intest. Microbiol., 51-58.

xxi. MacFarlane GT\& Cummings JH (1991) The colonic flora, fermentation, and large bowel digestive function. In Hand book of The Large intestine: Physiology, Pathophysiology, and Disease, pp 51- 92.

xxii. AAFCO (1993) Association of American Feed Control Officials Official Publication

xxiii. Chen TC (1992) Poultry meat microbiology. In Hand book of Encyclopedia of Food Science and Technology, pp. 2140-2145.

xxiv. Samah EL, Moustafa GZ, Anwer W, et al. (2014) Microbial Load of Poultry By-Products Following Rendering Process. Global Veterinaria 12 (6), 756- 759

xxv. Haapapuro ER, Barnard ND, Simon M (1997) Review Animal waste used as livestock feed: danger to human health. Prev. Med. 26, 599-602.

xxvi. Rundberget T, Skaar I \& Flåøyen A (2004) The presence of Penicillium and Penicullium mycotoxins in food wastes. Int. J. Food Micro. 90 (2),181-188.

xxvii. Lowe JA \& Kershaw SJ (1995) Water activity-moisture content relationship as a predictive indicator for control of spoilage in commercial pet diet components. Animal Feed Science and Technology 56,187-194. 